\title{
Acerca da guerra e da paz nas crônicas jesuíticas das reduções: o caso da conquista espiritual de Montoya
}

\author{
MARIA CRISTINA BOHN MARTINS*
}

Resumo: As fontes jesuíticas são um importante veículo para a compreensão de vários aspectos da história das atividades missionárias dos inacianos e de sua interação com os nativos do Novo Mundo. Este trabalho analisa as percepções elaboradas sobre o tema "guerra e paz" na crônica do padre Antônio Ruiz de Montoya, escrita no momento em que violentas incursões bandeirantes ameaçavam a própria existência das Reduções.

\begin{abstract}
The Jesuits's work has been an important source of information for the understanding of some aspects of the activities of the missionaries and their interaction with the native people (Indians) of the "New World" (America). This essay examines how the theme "war and peace" appears on Montoya's work. His chronicle was written at the time several violent raids by "bandeirantes" were threatening and attacking the "reduções" (Jesuit Missions).
\end{abstract}

Palavras-chave: Montoya. Missões Jesuíticas. Guerra e Paz.

Key words: Montoya. Jesuit missions. War and peace.

\section{Os guaranis e a guerra}

Desde a época pré-hispânica, a província do Paraguai encontrava-se povoada por grupos indígenas, pertencentes à grande família Tupi-guarani. Estes, aparentemente nos inícios da nossa era, migraram da Amazônia e fizeram das áreas de bons solos da floresta subcadocifólia subtropical e tropical do sul do Brasil, seu habitat por excelência. Num processo de "colonização dinâmica", estenderam rapidamente sua área de ocupação e foram deslocando

\footnotetext{
Doutora em História pela PUCRS, professora Titular do Programa de PósGraduação em História da Universidade do Vale do Rio dos Sinos - UNISINOS. E-mail: mcris@unisinos.br
}

Estudos Ibero-Americanos. PUCRS, v. XXXIII, n. 1, p. 133-148, junho 2007 
ou incorporando populações de economias mais simples. Ocuparam, assim, as áreas entre os rios Paraguai e Paraná, as margens do Rio Uruguai e também as ilhas do Paraná até a embocadura do Prata. O Rio Paraguai constituía-se, então, numa fronteira cultural e ecológica potencialmente conflitiva, envolvendo os caçadorescultivadores guaranis, que viviam em aldeias constituídas por linhagens aparentadas entre si e ocupavam sua margem oriental, e os nômades guaicurus e payaguás, na margem oposta.

De acordo com André Luis Soares (1997), podemos discriminar distintos graus de complexidade na organização social guarani, com seus correspondentes em nível das lideranças de cada um destes graus. Num primeiro nível estaria a família extensa ${ }^{1}$ ou teýy, que poderia albergar até sessenta famílias nucleares, e cuja liderança está relacionada ao "pai da linhagem" ou teýy-ru; a seguir encontramos a aldeia ou amundá, como espaço social que reúne as famílias extensas, sendo o tuvichá ${ }^{2}$ o seu principal. A reunião das famílias extensas em povoados estreitava os vínculos de parentesco e reciprocidade, além de contribuir para a proteção e segurança da coletividade. Um conjunto das aldeias e o seu território de domínio formava o teko'a, e o conjunto destes, províncias ou guarás, como expressão de uma área de maior abrangência. Cada uma destas províncias representava a região sobre a qual estavam implícitos o direito à terra cultivável e à exclusividade das zonas de caça, de certa forma determinando os limites dos deslocamentos das famílias em busca de novas roças. Aos guarás estaria associado o termo tuvichá-ruvichá ou mburuvichá, expressando a idéia de "cacique entre os caciques" (Soares, 1997, p. 122-123). Constituindo-se em territórios geográficos bem definidos, os guarás conformavam, à época da Conquista espanhola, províncias designadas por nomes próprios: Cario, Tobatin, Itatim, Guarambaré, etc. (SUSNIK, 1990).

Montoya, ao referir-se à Província de Tayoaba, esclarece: "Este era o nome de um dos caciques principais, governador de muitos povos, do qual toda aquela província tomou seu nome próprio. [...]. Tinha ela um número de gente quase infinito, a qual [...], era muito guerreira e possuía a prática de comer carne humana” (1985, p. 110).

1 Ainda segundo este autor, embora a família nuclear seja reconhecida entre os guaranis, ela não é entendida como célula mínima da organização social do grupo (Ver: SOARES, 1997, nota 259).

2 O termo foi registrado por Montoya no seu Tesoro de la Lengua Guarani: (1639; 1876) Tuvichá (principal), assim como mburuvicha (el que contiene en si grandeza, Principe o Señor) (apud: Soares, 1997, nota 256). 
No interior do guará reinava uma reciprocidade positiva, evidenciada especialmente através da rede de convites para as grandes festas que reuniam os parentes e aliados, e consolidavam os laços sociais e as alianças políticas. Igualmente importante era a conjugação de esforços para a defesa territorial, uma vez que "todo el espacio externo fuera de la Guará estaba atravesado por la violência interétnica, la resistencia intertribal defensiva y la antropofagia que instauraba la sed de venganza y la reciprocidad negativa como forma de relación social con los enemigos" (Avellaneda, 2005, p. 20).

Entre estes inimigos estavam, a oeste do Rio Paraguai, na região do Chaco, os já referidos guaicurus, que periodicamente assaltavam as aldeias guaranis em busca de alimentos e mulheres; ao norte do mesmo rio, dominando seu curso superior, viviam os paiaguás e, na região oriental, ao longo da costa atlântica, os tupis. $^{3}$

Para Avellaneda, os guaranis "inmersos en un estado conflictivo de guerras con las tribus vecinas, conformaban una sociedad de guerreros, donde la destreza y el coraje en los enfrentamientos constituían los valores más preciados" (Avellaneda, 2005, p. 21). Por isto, convocar aliados para as guerras, exercer a vingança, assim como o dom, estavam na base da autoridade dos seus morubixabas.

\section{A guerra guarani nas fontes primeiras}

A primeira referência histórica conhecida ${ }^{4}$ para estes grupos, sobre os quais prevalecerá o nome da língua que compartilhavam, o guarani, data de 1528. Ela foi formulada por Luis Ramirez, um dos exploradores que acompanhavam a expedição Sebastião Caboto, e assinalava: "Aqui con nosotros está otra generación que son nuestros amigos, los cualles se llaman Guarenís [...]: éstos andan dellamados por esta tierra, y por otras muchas, como corsarios a causa de ser enemigos de todas estotras naciones [...] son gente muy traidora [...] estos señorean gran parte de la India y confinan con los que habitan la Sierra" (apud: Meliá, 1987, p. 21).

3 Embora não seja nosso objetivo analisar aqui esta situação, há que se referir, também, sobre os conflitos inter-grupais suscitados pelo rapto de mulheres ou por disputa pelos territórios de caça.

4 A não ser que se queira considerar aquela de Gonenville sobre os índios da costa catarinense. Ver: Revista Trimestral do Instituto Geographico e Etnographico do Brasil. Rio de Janeiro: 2 tomos XLIX, 1886. 
Um pouco posteriores, as observações de Ulrico $S_{c h m i d l}{ }^{5}$ reiteram esta percepção acerca da presença guarani por extensas áreas, ${ }^{6}$ bem como o relevo que davam eles à atividade guerreira. ${ }^{7}$ Schmidl revela, ainda, o quanto os povoados guaranis constituíam-se em espaços sociais bem defendidos contra o assalto dos inimigos: as aldeias eram rodeadas por uma dupla paliçada circular formada por grandes postes de madeira e separadas por um fosso em que lanças de pontas afiadas eram escondidas por meio de ramas e terra (Schmidl, 1985, p. 155-156 e 192).

O conjunto das notícias produzido neste contexto inicial - de uma "etnologia da conquista", de acordo com Meliá - pode ser dividido em dois momentos, sendo o primeiro aquele em que os índios aparecem como potenciais aliados na exploração dos caminhos para a cobiçada Serra da Prata (Ramirez, 1528; Diego Garcia, 1530; Schmidl, 1534; e Cabeza de Vaca, 1542). Logo depois, à medida que se afirmava a situação colonial e era implantado o regime da encomienda, a precária aliança anterior dá lugar a relações de conflito e rebeliões indígenas (Meliá, 1987, p. 21-23). Em ambos os casos, é compreensível que o comportamento belicoso dos nativos chamasse a atenção de seus contactadores iniciais, assim como também ocorreu entre os missionários da Cia. de Jesus que, em suas primeiras incursões entre os guaranis, observaram e registraram notícias a este respeito.

Dentre os escritos dos jesuítas da Província do Paraguai, ${ }^{8}$ aqueles que procedem dos anos iniciais são os mais ricos no que se poderia definir como seu "conteúdo etnográfico". É claro que, como tem salientado Meliá (1988), as referências aos índios aparecem sempre em contraste com o que se entendia (e pretendia) como vida "humana", e não se pode ler o registro missionário fora desta

5 Protagonista dos momentos iniciais da conquista do Prata, Schmidl participou da expedição de Pedro de Mendoza e da primeira fundação (1536) de Buenos Aires, assim como da de Asunción (1537) (ver: Schmidl, 1985, p. 129-225).

6 "Estos Carios dominan um gran territorio: yo creo, y de esto estoy cierto, que abarca más de trescientas leguas a la redonda" (Schmidl, 1985, p. 155).

7 Após tentativa mal-sucedida de dar combate aos espanhóis liderados por Ayolas, os guaranis refugiaram-se no interior bem defendido da aldeia de onde resistiram ao assalto "y se defendieron muy valientemente..." dos espanhóis. Derrotados, participam com os cristãos do ataque contra os agaces. Suas práticas nesta oportunidade, renderão do cronista o seguinte comentário: "Los Carios son un pueblo así, que matan a cuantos encuentran en la guerra frente a ellos, sin tener compasión con ningún ser humano" (Schmidl, 1985, p. 158).

8 Estamos aqui nos referindo à Província Jesuítica do Paraguai, criada em 1607, e que, por vezes, aparece na documentação também sob o nome de Paracuaria. A Governação e Província administrativa do Paraguai, abrangia, na época colonial, limites bastante mais extensos que os da moderna República de mesmo nome. 
perspectiva. É este o caso de um Informe, ${ }^{9}$ datado de dezembro 1620, em que o missionário, expressando sua convicção de que a catequese era o caminho para redimir os guaranis dos vários vícios aos quais estavam submetidos, ${ }^{10}$ não só reafirma observações anteriores sobre as relações entre eles e as demais etnias da área, como noticia o estado de conflitividade estabelecido com os povoadores espanhóis, ${ }^{11}$ a qual acentuou-se a partir da concessão das primeiras encomiendas ${ }^{12}$ na área.

Es gente valerosa en la guerra y donde quiera que estan tienen sujetas las naciones çircunveçinas. Son altivos y soberbios y a todas

9 Relacion en que se da cuenta de las ciudades de la gobernación del Paraguay y de sus indios y del estado q. tinenen por el mes de desiembre de 1620 años en respuesta de lo q. a cerca desto pregunto su mag.d.. (In: MCA I, 1951, p. 162 -172).

10 A estos indios les oponen que son borrachos, olgaçanes, hechizeros mentirosos y siempre estan pensando en maliçia y en trayciones, y otros mill males que les imponen. (...) esto es lo que pretende remediar dios nuestro Señor y el papa su vicario por medio del rey nuestro señor para cuya enseñanza sustenta su majestad los obispos y sacerdotes y enbia a su costa tanta cantidad de religiosos y en las mismas cedulas de encomiendas manda a los encomenderos que les den dotrina y policía christina encargandoles la concieçia y es çierto que si en su cultivo se hubiera puesto cuydado, que o no tubieron estos viçios o fueron muy moderados. (...)" (MCA I, 1951, p. 168).

11 Importa frisar que, para o missionário, tanto quanto os guaranis, também os espanhóis parecem estar fora do que se entendia como vida humana: "Viendose los españoles abundosos en comida de la tierra, y con tantas mancebas no aspiraron a mas, contentandose con un poco de lienço de algodón teñido de negro para su vestido: e como estaban en el Parayso de mahoma se governaban a su modo, y assi su govierno mas era despotico y tiranico que politico, y christiano, prendiendose y matandose unos a otros, y casi hasta ahora dura este gobierno despotico porque cualquiera cosa que haya menester la Justiça de hacienda agena se la toma sin tratar de paga, solo con decir que conviene al serviçio de su majestad..." (MCA I, p. 163). "Los españoles de esta tierra como casi todos tocan en indio salen en mucha cosa a sus aguelos y assi son enemigos del trabajo, inconstantes en lo que emprenden, descuydados, no miran mas de a lo presente: dan con facilidad lo que tienen y son grandes pedidores entre si; y de aqui nasce que todo el pueblo esta caydo y deshabitado viviendo todo el año en las chacaras o haçiendas que tienen, sino en las fiestas y essas no son todas, y se suelen meter quatro y seis hombres casados en una choçuela que no caben de pies, y en oyendo missa se vuelven al campo. Y con tener tanta abundancia de madera y tan cerca y mucho aparejo para haçer teja y muy buena no se applican a nada ni los que goviernan atienden a ello como si no les tocara. (...). Los naturales de esta tierra son dóciles y habiles quando muchachos y quando van creciendo se van haçiendo broncos y entiendo que lo causa la poca dotrina y policía que tienen en sus casas, porque como todos estan juntos y rebueltos primero saben pecar que tengan entero uso de raçom" (MCA I, 1951, p. 164).

12 Até 1556 as relações de cuñadazgo estabelecidas entre os guaranis e os espanhóis foram a base para a utilização da força de trabalho dos primeiros pelos segundos. Esta situação será profundamente alterada a partir de 1556 quando for institucionalizado o regime da encomienda, com a distribuição, pelo governador D. Martinez de Irala, de cerca de 100.000 índios entre 300 espanhóis (Ver: Necker, 1990, p. 37). 
naçiones llaman esclavos sino es al español, pero no le quiere llamar señor sino cuñado o sobriño porque diçen que solo dios es su señor. Porque como he dicho el ayudar al español y admitirle en sus tierras fue por via de cuñadasgo y parentesco. Empero después viendo los indios que los españoles no los trataban como a cuñados y parientes sino como a criados se començaron a retirar y no querer servir al español. El español quiço obligarle: tomaron las armas los unos y los otros y de aquí se fue encendiendo la guerra la qual ha perseverado casi hasta agora (MCA I, 1951, p. 166).

La Provincia del Parana es toda gente Guarani gente Bellicosa que siempre ha sustentado la guerra contra el español. Estos indios tenian sujetas todas las naçiones que estaban el rio Parana abajo y muchas veçes tubieron a ponto de despoblar la çiudad de san juan de vera. También tenían tomado el passo de este Rio del Paraguay de manera que no se podia entrar ni salir sino con escolta de gente y a veçes con todo este resguardo quedaban muertos o pressos los que navegaban este rio. Esta provincia nunca tubo sacerdote ni tampoco sé que se aya tratado de su conversión el año (¿??) que entro la compañía en sus tierra(s...) (MCA I, 1951, p. 169).

Documentos desta ordem, assim como as cartas anuas, referentes às primeiras "fundações", ao registrarem momentos de encontros iniciais junto à parcialidades ainda pouco ou nada conhecidas pela sociedade ocidental, possibilitam, pois, uma "entrada" junto ao guarani ainda não conquistado e reduzido. Em boa parte, elas se referem a circunstâncias de intenso conflito, não apenas quanto à oposição estabelecida por lideranças indígenas frente à proposta de redução com que lhes chegavam os padres, como, ainda, quanto aos ataques dos bandeirantes aos povoados do Guairá, Itatim e Tape.

É este o caso, também, da Conquista Espiritual, escrita em 1639 pelo limenho Antônio Ruiz de Montoya. Encaminhado ao Guairá em 1611, ele iniciou aí seu trabalho missionário, juntamente com padres Joseph Cataldino e Simon Masseta que haviam, então, erigido dois primeiros povoados na região: Santo Inácio e Nossa Senhora de Loreto. ${ }^{13}$

13 Em 1620, Montoya tornou-se o Superior Geral das Reduções, e em 1638 foi enviado por seus superiores à Madrid, a fim de peticionar, ante a Corte de Felipe IV, medidas em defesa dos guaranis que sofriam as conseqüências dos ataques bandeirantes. $\mathrm{Na}$ oportunidade, escreveu e publicou (1639) a relação acerca das Reduções, intitulada La Conquista Espiritual. 


\section{A Conquista Espiritual de Montoya}

Apesar da sua importância como um registro de primeira mão sobre as atividades missionárias, $A$ Conquista não é uma obra de história, e as suas imprecisões, seu pouco apego à cronologia, bem como, e especialmente, as suas constantes referências ao sobrenatural, não recomendam que ela seja consultada nesta expectativa. Também não é fácil propor-se a ela uma leitura em busca de claras descrições etnológicas. ${ }^{14}$ Quase invariavelmente, as características do "modo de ser" guarani (Meliá, 1987) aparecem apenas na medida em que elas se apresentam em contraste com o que vinha ser o objetivo da ação missionária: a "modelação" moral e espiritual dos nativos.

Montoya, contudo, é um observador arguto. Ele esclarece, por exemplo, que, embora vivessem em povoações pequenas, não faltava aos guaranis um sistema de chefia e autoridade, ${ }^{15}$ relativizando, assim, a impressão dos primeiros cronistas espanhóis acerca da organização - ou falta de organização - política das populações com as quais iam entrando em contato. Muitas vezes, a elas foi associado o termo behetría que, derivado do antigo vocabulário jurídico castelhano, tornou-se, na América, sinônimo de desordem e confusão. Sabemos que, ao lado do dom da eloqüência e da possibilidade de manifestar prodigalidade, como ao estabelecer os convites para as festas, a valentia e a qualidade guerreira ${ }^{16}$ eram atributos essenciais para afirmar uma posição de liderança frente ao grupo. Estes "principais" ocupam a atenção do autor em vários momentos, seja na qualidade de opositores aos padres, seja como

14 Exceção talvez feita ao seu capítulo X, "Sobre os ritos dos guaranis", que oferece uma descrição mais sistematizada de importantes aspectos acerca dos índios.

"Viviam, e hoje ainda vivem os gentios em povoações muito pequenas, (...), mas não sem governo. Tinham eles seus caciques, em quem todos reconhecem nobreza herdada de seus maiores, com o fundamento de que haviam tido vassalos e governado povo" (Montoya, 1985, p. 52).

16 Ao descrever os "preparativos para a guerra" empreendidos pelo Cacique Miguel Artiguaye, contrário à presença dos padres, Montoya descreve a pompa e o cuidado com que eles se preparavam para investidas desta natureza. Artiguaye opunha-se à presença dos missionários, especialmente depois que estes passaram a pressionar para que as várias esposas de que dispunha fossem repudiadas em favor de uma delas: "Que espécie de doutrina é esta que nos trouxestes? Qual o descanso (a paz) e o contentamento? Nossos maiores viveram com liberdade, tendo para seu bem as mulheres que queriam, sem que ninguém nisso os estorvasse, com as quais viveram e passaram os seus dias com alegria. Vós, no entanto, quereis destruir as suas tradições e impor-nos uma carga tão pesada, como é a de atar-nos com uma só mulher. Já não se pode agüentar a liberdade dos que, em nossas próprias terras, querem levarnos a viver segundo sua ruim maneira de vida!” (Montoya, 1985, p. 58). 
seus aliados, aos quais os jesuítas, aliás, reconhecem como fundamentais para o sucesso de suas ações.

Os relatos da Conquista cobrem, como dissemos, um período de tempo marcado por intensos conflitos que se estabelecem, tanto opondo os guaranis das reduções a outros índios não convertidos, quanto por conta dos assaltos dos bandeirantes provenientes do espaço luso-brasileiro. Desta forma, podemos, no primeiro caso, acompanhar que as entradas dos padres em territórios de grupos que pretendiam reduzir, e para as quais se faziam acompanhar de contingentes de guaranis neófitos, podiam desencadear ferozes combates ${ }^{17}$ entre os índios de um e de outro lado.

Quando nem a cooptação dos chefes locais, nem a força das armas eram suficientes, a Providência Divina, agindo pela mão dos padres, era o instrumento capaz de "amansar leões, domesticar tigres, e fazer de feras selváticas homens e até mesmo anjos" (Montoya, 1985, p. 168). "Por armas essa gente foi inconquistável; conquistou-a, contudo aquele varão apostólico ${ }^{18}$ apenas com o Evangelho, e com a caridade e paciência de Cristo", afirma Montoya, sobre os índios da província do Paraná, aldeados em Santo Inácio. No mesmo sentido, ele se refere ao povoado de Encarnação: "foi esta gente que fez guerra ferrenha à redução anterior, pelo fato de ela ter recebido o Evangelho" (Montoya, 1985, p. 176 e 179, respectivamente).

Percebe-se que a oposição mata versus redução, serve nele, como em outros textos jesuíticos da época, para criar ou dizer diferenças qualitativas recorrentes, reforçando constantemente as atitudes belicosas do gentio ainda não tocado pela graça da conversão. $\mathrm{O}$ batismo e a vida nas comunidades cristãs das reduções aparecem aqui como um corte, a demarcar o diferencial entre uns e outros, bem como sobre as guerras que fazem uns e outros.

Isto porque, se as guerras tribais eram sinônimas de barbárie, elas encontram justificação no momento em que se fazem em torno da defesa dos princípios e interesses sustentados pelos missionários, como é o caso de ações de proselitismo que contam com o apoio de índios das reduções. É, também, o que se verifica quando da expedição punitiva organizada em 1635 contra os responsáveis pela morte do Padre Cristóvão de Mendonza, um dos agentes da

17 É o que acontece quando da tentativa de Montoya de catequizar a gente da Província de Tayoaba. Embora contando com a adesão do principal da região, Montoya e seu grupo terão de enfrentar a oposição de Guiraberá e daqueles que o seguem, os quais entraram em combate com os índios que acompanhavam o missionário.

18 Montoya está referindo-se a Marcial de Lorenzana, fundador da Redução de Santo Inácio. 
expansão das reduções pelo Tape: "Para vingá-lo, apresentaram-se logo mais de 1400 índios de guerra, recomendando-lhes os padres que não fizessem mal a ninguém, mas tratassem apenas de resgatar o corpo do santo padre. Acharam eles os inimigos mais que prevenidos, os quais investiram com grande ímpeto contra os nossos. Mas, rechaçados pela primeira vez, juntou-se um número ainda maior. Na segunda fizeram os nossos uma matança muito cruel, sendo que entre eles morreram todos os que haviam martirizado o padre" (Montoya, 1985, p. 236). Ao líder do líder do grupo refratário aos jesuítas, Tuyubay, o cacique Guaybicang de São Miguel, reservou o castigo comum aos inimigos de guerra, quebrando-lhe a cabeça com um porrete.

Apesar dos possíveis excessos cometidos pelos índios em combate, como neste caso, os jesuítas em geral, e Montoya em particular, insistem na diferença entre a gente selvagem que vive na mata, e a gente pacífica que vive nas áreas abertas da redução. Percebe-se, contudo, que embora sejam sempre reforçadas as atitudes belicosas daqueles ainda não convertidos, ${ }^{19}$ mesmo o "exército de fiéis" podia cometer excessos, o que sugere que a ascendência que os padres tinham sobre os índios, tinha seus limites.

Logo após este evento, ele relata ter sido preciso mobilizar "um bom número de fiéis" para reprimir a ação de outro grupo que andava "pelos campos e montes em manadas, à maneira de cães selvagens", os quais, entrando nos povoados, "acometem como feras ao rebanho, fazendo suas presas em meio dos mocinhos, que conseguem pegar, para sua comida" (Montoya 1985, p. 237). Embora novamente possamos aqui observar a relação de opostos estabelecida entre virtude e selvageria, os vitoriosos guaranis não parecem ter dispensado caridade cristão aos derrotados, uma vez que o relato registra que "de gente infiel morta e cativa houve muita” (Montoya, 1985, p. 237). Vê-se que, na defesa de um modo de vida honesto, tal como considerava Montoya representarem as reduções, a guerra e a violência poderiam ser aceitos, como, também, que nem sempre a orientação dos religiosos era suficiente para controlar práticas tradicionais dos guaranis frente aos inimigos.

19 É o caso de Miguel Artiguaye, que ameaçava o povoamento de Santo Inácio em seus dias iniciais, buscando convencer a outros caciques da necessidade de expulsar os missionários da região. Segundo Montoya, os padres "como cordeiros", ouviam os "os uivos desse lobo": "Já não se pode agüentar a liberdade dos que, em nossas próprias terras, querem levar-nos a viver segundo sua ruim maneira de vida" (Montoya, 1985, p. 58). 
Também a resistência da Província de Tayoaba - em que organizaram-se "juntas" para responder à tentativa dos missionários de fundar ali um povoado - foi quebrada com a ajuda de guaranis das reduções. Tayoaba era "governador de muitos povos, do qual toda aquela província tomou seu nome próprio. [...]. Tinha ela gente em número quase infinito, a qual se achava com os costumes gentios em plena observância, era muito guerreira e possuía grande prática em comer carne humana" Montoya, 1985, p. 110). Contra a "fúria daqueles tigres", contudo, não teria sido a força das armas que conduzira a vitória, e sim o auxílio invocado pelo jesuíta aos Sete Arcanjos, a quem foi dedicada povoação:

Fundamos ali uma povoação de 2000 vizinhos e de covas de feras, em que se haviam visto senão bebedeiras, desonestidades, inimizades, mortes, banquetes de uns pelos outros ou canibalismos. [...]. Vivendo antes numa inquietude contínua, agora já feita aquela terra um paraíso, ouviu-se a palavra de Deus na igreja. Em suas casas, antes de adormecer, os índios rezavam em voz alta as orações e o mesmo faziam ao despertar. Em vez de afiarem os ossos humanos para suas setas, já lavravam ou fabricavam cruzes para as levarem ao pescoço (Montoya, 1985, p. 124).

Enquanto a guerra aparecia como medida última para tratar com grupos infiéis, e apenas quando a pregação e os presentes não tinham resultado, outro plano em que ela se faz presente ao longo do texto da Conquista, diz respeito à ameaça representada pelas incursões bandeirantes. As primeiras entradas dos paulistas em busca de índios dos povoados a serem escravizados, são noticiadas no capítulo XXXVIII e, especialmente a partir daquelas que se produzem desde 1636 sobre o Tape, ${ }^{20}$ ocorre uma importante inflexão nas representações elaboradas pelo missionário, passando os paulistas a ocupar, na qualidade de ameaça ao trabalho de evangelização, o lugar antes reservado ao gentio.

Na mesma medida, os qualificativos que anteriormente serviam para designar os grupos indígenas não cristãos, transferem-se agora aos paulistas que, em seus ataques, agem como "possessos do demônio", como "tigres ferozes" e "homicidas", inclusive contra povoações espanholas: "Cevados nos índios, aqueles lobos trataram de destruir aos espanhóis"21 (Montoya, 1985, p. 246). O jesuíta, que não levanta dúvidas acerca da sincera conversão dos ín-

20 O primeiro ciclo atingira o Guairá em 1628.

21 Ataques também ocorreram às povoações espanholas de Vila Rica e Ciudad Real, igualmente devastadas. (Montoya, 1985, p. 246). 
dios, questiona a própria fé dos bandeirantes (e dos sacerdotes que os acompanham), a quem acusa até mesmo de sacrilégio.

Podemos inferir que, enquanto sua representação dos guaranis oferece facetas mais complexas, não havendo uma, mas várias imagens suas presentes na Conquista (sendo o guerreiro altivo e ameaçador e o catecúmeno dócil as mais exemplares), os bandeirantes aparecem como o outro absoluto e fonte de toda maldade. Por sua vez, assim como as reduções são o contraponto da vida na selva, São Paulo, de onde se originam as expedições, aparece como espaço que permite estar fora das normas de virtude e humanidade: lugar onde agregaram-se aqueles que querem viver "com liberdade e desafogo e sem qualquer aprêmio da virtude" (Montoya, 1985, p. 125).

O perigo representado pelos bandeirantes foi refreado a partir de 1641. Obtida a licença para armar os índios das reduções, estes imporão, neste ano, uma severa derrota à expedição de Manoel Pires na batalha de M'bororé, que foi decisiva para conter a expansão luso-brasileira e firmar a área de ocupação dos povoados. Mais que isto, organizados em milícias treinadas no uso de armas de fogo, os índios das aldeias serão convocados, sistematicamente, ao longo das décadas seguintes, para prestação de serviços militares, dando oportunidade a que o tema da "guerra e paz", continuasse freqüentando com regularidade as crônicas e escritos jesuíticos.

Eduardo Neumann (1996) demonstrou a constância com que foram chamados índios das reduções para servirem ao poder público colonial em obras ou em "auxílios militares", evidenciando o quanto as aldeias eram parte integrante da sociedade colonial. Afirma ele que "durante os séculos XVII e XVIII, foram expedidas diversas ordens por parte dos Governadores, solicitando aos Padres Provinciais que enviassem índios das reduções para auxiliarem contra possíveis invasões de nações estrangeiras e ataques de índios infiéis, ou ainda para participar das obras públicas, na escolta de governadores, no patrulhamento das terras rio-platenses, bem como no fornecimento de armamentos e apetrechos de guerra, contribuindo, por vezes, com mantimentos para as tropas em campanha" (Neumann, 1996, p. 77).

Na documentação relativa a este período, que não está contemplado na Conquista Espiritual, o depoimento dos padres acolhe como fundamental a bravura guarani em combate, seja contra os paulistas, seja contra "índios infiéis", seja contra os povoadores de Sacramento. 
Hace cosa de 70 anos que sucedió esta última batalla. Desde entonces no han osado volver, y han quedado los pueblos en pacífica posesión de sus tierras y libertad. [...]. Son estes índios muy aptos para la guerra si se ejercitan en las armas. Bien lo mostraron en las batallas de los Portugueses Mamelucos hasta derrotar todo al ejército mayor y más bien armado de gente blanca que se ha juntado en esta tierra (Cardiel, 1953, p. 153 e 157, respectivamente).

Jose Cardiel, ${ }^{22}$ por exemplo, autor de uma Relación de 1747 sobre as reduções, refere-se às várias contribuições destes na defesa dos interesses das autoridades locais. Assim, quando acionada neste propósito, a belicosidade dos índios é motivo de elogios, como no caso das investidas bem sucedidas feitas ao entreposto português de Sacramento, ou contra outras etnias que desestabilizavam a presença espanhola no Prata:

Antecedentemente fueron 600 indios a la banda del Paraná, llamados de los Españoles de Santa Fe para defenderlos de las insuperables invasiones de los Calchaquíes. Portáronse con gran valor, matando y prendiendo a tantos que quedó sosegada la tierra. Fueron en otra ocasión a castigar los contínuos insultos de los Caracarás, que vivían al Sur de las Corrientes entre los dos ríos, y casi acabaron con ellos, y ahora ni aun el nombre hay de esta nación. [...]. Pocos años há que pidieron los Españoles de Corrientes 600 Guaraníes, para que les ayudasen a castigar a los Charrúas amotinados. Previnieron todos armas de fuego y fierro; y estando para partir avisaron los de las Corrientes que ya no era menester, porque los amotinados, de miedo, habían hecho las paces (Cardiel, apud Furlong, 1953, p. 158).

Podemos, também, encontrar os guaranis combatendo grupos (yaros, guenoas, minuanos e charruas) que ameaçavam os pró-

22 Cardiel foi um dos mais destacados membros do grupo que recebeu, no Paraguai, a ordem de expulsão de 1767. Havia chegado ao Prata em 1729 e, dois anos depois, foi designado para trabalhar nas Reduções, onde passaria duas grandes temporadas, uma de 12, outra de 16 anos. Na primeira delas, participou de importantes acontecimentos, como quando foi capelão das milícias guaranis que lutaram contra os "comuneros" de Assunção entre 1734-1735. Sua posição crítica contra as disposições do Tratado de Madrid, custou-lhe a proibição de escrever ou falar sobre o assunto. Sob estrita vigilância, foi incumbido da pacificação dos índios rebelados, e de acompanhar os demarcadores e o exército espanhol. Será ainda encarregado da reconstrução da Missão de São Miguel, o maior dos povoados ocupados pelas forças portuguesas. A saúde debilitada foi a causa que invocou para solicitar ser dispensado de suas atividades, pelo que foi designado para o povoado de Concepção, onde se encontrava quando, em 10 de agosto de 1768, foi detido e embarcado, junto com outros 30 jesuítas, para a Espanha, onde aportou em meados de abril de 1769. Pouco depois foi enviado para a Itália, radicando-se em Faenza como a maioria dos membros da antiga Província do Paraguai. 
prios povoados jesuíticos. "Todos fueran vencidos con gran estrago; y los pocos que quedaron, parte se han hecho cristianos, agregandose a los pueblos de los vencedores [...], y se está tratando continuamente de su conversión, aunque que con poco fruto, por ser de a caballo y sin sementereas perpetuas, vagamundos como tártaros, árabes y gitanos" (Cardiel, apud Furlong, 1953, p. 158).

As milícias guaranis das missões são apresentadas por Cardiel, como "la única fuerza efectiva y pronta que tienen los Españoles y el Rey para todo acometimiento de enemigos; y tan leales, que jamás han repugnado a cosa del servicio del Rey" (Cardiel, apud Furlong, 1953, p. 158-159). Percebe-se que o exercício retórico do missionário não se dirigia unicamente a evidenciar a importância do serviço militar dos índios, mas afiançar continuamente sua lealdade e, mais ainda, que esta lealdade tinha a mediação dos padres. A tônica conferida por Cardiel ao seu texto, se explica pela situação, então estabelecida, de desconfiança e acusações levantadas contra a Companhia e que, no limite, conduziriam, logo depois, à expulsão dos missionários dos territorios coloniais.

Aunque algunos españoles dicen que no hay más Dios ni más Rey para ellos que los Padres, conocen muy bien quién es el Rey, porque les predicamos mucho en orden a la obediencia con que le deben respetar; $[. .$.$] . Le nombran en sus alardes gritando: toicobengahí$ ñande Rey, viva nuestro Rey. Le tienen pintado en las Armerías; y cuando en tiempo de alguna función militar preguntan a alguno ¿quién eres? si es de los senalados para la función, luego dice; yo soy soldado de nuestro Rey. En sus pláticas o razonamientos que hacen los principales, suelen repetir: dos Reyes tenemos, uno en el cielo, otro en la tierra; y explican la obediencia que se debe tener al uno y otro (Cardiel, apud Furlong, 1953, p. 159).

As circunstâncias que especificam a confecção da Conquista as dificuldades iniciais da catequese e do aldeamento dos índios, os ataques bandeirantes e a necessidade política de obter respaldo da Corte - não impedem que ela sirva para informar acerca de elementos importantes sobre as práticas de guerra dos índios. Embora a obra não os tenha como objeto, e sim o protagonismo dos jesuítas ou, quem sabe, da própria Providência Divina, agindo pelas suas mãos, ela nos permite perceber alguns elementos centrais das práticas de guerra dos guaranis, tais como o papel das lideranças e da vingança, a importância das alianças, dos "alardes" e das convocatórias. Ela também serve como referência para pon- 
tuar questões como a da busca de uma "identidade guarani", pois que as ações do grupo aparecem aqui cindidas em conflitos de interesse entre os partidários das reduções e seus oponentes. Neste sentido, a Conquista Espiritual nos convida a que reflitamos, seguindo os passos de Regina Celestino de Almeida (2002), sobre os complexos processos de adaptação, mas também de negociação, protagonizados por missionários e indígenas.

Cabe considerar, ainda, sobre a documentação jesuítica, que o que a especifica, como discurso religioso, literatura edificante ou argumento político, mais que um elemento de deformação, deva ser o ponto de partida de sua análise. Trata-se essencialmente de um conjunto de escrita religiosa, dado que é elaborada dentro dos marcos de uma instituição religiosa, e compõe uma mensagem devocional que deve ser reconhecida pelos irmãos espalhados pelo mundo. De outro lado, não deixa de ser instigante a reflexão sobre o quanto e como os problemas específicos de cada missão podiam interferir nesta construção formal. Sabemos bem que a produção historiográfica é sempre fruto de sua época e, desta forma, dinâmica. Este dinamismo se enlaça não apenas com o descobrimento de novas fontes, senão também com a possibilidade de conferir-lhe leituras e interpretações que se atualizam. É assim imprescindível que as "chaves" de decodificação das fontes jesuíticas sejam a primeira consideração do historiador a seu respeito.

\section{Referências bibliográficas}

ALMEIDA, Maria Regina Celestino. Metamorfoses Indígenas. Identidade e cultura nas aldeias coloniais do Rio de Janeiro. Rio de Janeiro: Arquivo Nacional, 2003.

ASSUNÇÃO, Paulo de. Negócios jesuíticos. O cotidiano da administração dos bens divinos. São Paulo: EDUSP, 2004, p. 227.

AVELLANEDA, Mercedes. El ejercito guarani de las reducciones jesuítas del Paraguay en el siglo XVII. História Unisinos, v. 9, n. 1, 2005, p. 19-34.

CABEZA DE VACA, Alvar Nuñez. Naufragios y Comentários. Madrid: Alianza, 1985 (edición de Roberto Ferrando).

CARDIEL, Jose. Las misiones del Paraguay. Madrid: Historia 16, 1989 (edición de Héctor Sáenz Ollero).

DAMIANE, Gisele T. Maciel. O Guarani: uma experiência de guerra. Porto Alegre: Pontifícia Universidade Católica do Rio Grande do Sul, 1996 (dissertação de mestrado).

EISEMBERG, José. As missões jesuíticas e o pensamento político moderno: encontros culturais, aventuras teóricas. Belo Horizonte: UFMG, 2000. 
FEDERMANN, N. Alemanes en América. Madrid: Historia 16, 1985 (edición de Lorenzo E. López), p. 129 - 225.

FRANZEN, Beatriz V. Jesuítas portugueses e espanhóis no sul do Brasil e Paraguai coloniais. São Leopoldo: Ed. da UNISINOS, 2003.

FURLONG, Guillermo S. J. José Cardiel S. J. y su Carta Relación (1747). Escritores Coloniales Rioplatenses II. Buenos Aires: Libraria del Plata, 1953.

HERNÁNDEZ, Pablo. Organización social de las doctrinas de guaraníes de la Compañía de Jesus. Barcelona: Gustavo Gilli, 1913.

IMOLESI, Maria Elena. Santos y herejes en los confines del imperio: la alteridad en los textos misionales jesuítas del siglo XVII. In: Jesvitas: 400 anos en Córdoba. Congreso Internacional, 21-24 septiembre, 1999. Córdoba/Argentina, 4 tomos, 2000. (t. 4).

KERN, Arno A. Missões: uma utopia política. Porto Alegre: Mercado Aberto, 1982.

LACOUTURE, Jean. Os Jesuítas. A Conquista. Lisboa: Estampa, 1993.

MANUSCRITOS DA COlEÇÃO DE ANGELIS I. Jesuitas e Bandeirantes no Guaira (15491640). Introdução, notas e glossário por Jaime Cortesão. Rio de Janeiro: Biblioteca Nacional, 1951 (MCA I).

MELIÁ, Bartomeu. El Guarani. Conquistado y Reducido. Ensayos de Etnohistoria. Asunción: Centro de Estudios Antropológicos/Universidad Católica, 1987.

MELIÁ, Bartomeu, TEMPLE, Dominique. El don, la venganza y otras formas de economía guaraní. Asunción: CEPAG, 2004.

MONTOYA, Antonio Ruiz de. Vocabulario y Tesoro de la lengua guarani (ó mas bien tupi). Publicado nuevamente sin alteración algúna por Julio Platzmann. Leipzig: Imprenta W. Drugulin, 1876.

MONTOYA, Antonio Ruiz de. Conquista Espiritual. Feita pelos religiosos da Companhia de Jesus nas Províncias do Paraguai, Paraná, Uruguai e Tape. Porto Alegre: Martins Livreiro Editor, 1985.

NOELLI, Francisco S. Por uma revisão das hipóteses sobre os centros de origem e rotas de expansão pré-históricas dos Tupi. Estudos Ibero-Americanos, vol XX, n. 1, p. 107-135, 1994.

NECKER, Louis. Índios Guaranies y Chamanes Franciscanos: las primeras reducciones del Paraguay. Asunción: Bilbioteca Paraguaya de Antropología/Centros de Estúdios Antropológicos, 1990.

NEUMANN, Eduardo. O trabalho guarani-missioneiro no Rio da Prata Colonial. Porto Alegre: Martins Livreiro, 1996.

REVISTA TRIMESTRAL DO INSTITUTO GEOGRAPHICO E ETNOGRAPHICO DO BRASIL. Rio de Janeiro: 2 tomos XLIX, 1886.

SCHMIDL, Ulrico. Relación del viaje al Río de la Plata. In: Alemanes en América. Madrid: Historia 16, 1985 (edición de Lorenzo E. López), p. 129-225. 
SOARES, André. Guarani. Organização social e arqueologia. Porto Alegre: EDIPUCRS, 1997.

SUSNIK, Branislava. Guerra, Transito, Subsitencia. Ambito americano. Asunción: Museo Etnográfico Andrés Barbero, 2000.

TORRES LONDOÑO, Fernando. Escrevendo cartas: jesuítas, escrita e missão no século XVI. Revista Brasileira de História. São Paulo: ANPUH/Humanitas Publicações, v. 22, n. 42, 2002, p. 11-32. 